\title{
The Impact of Official Development Assistance on the Productivity of Agricultural Production in Ghana, Cameroon and Mali
}

\author{
Petr Blizkovsky¹, Roman Emelin² \\ ${ }^{1}$ General Secretariat of the Council of the European Union, Brussels, Belgium \\ ${ }^{2}$ Mendel University, Brno, Czech Republic
}

\begin{abstract}
African economies depend largely on agriculture. Most people in Africa spend most of their lives in rural areas. Agriculture is an important sector of African industry and economy, it employs more than half of the population and accounts more than half of the national income. Due to population increase the food security remains an issue. In accordance of the lack of domestic capacities of African countries to deal with the problem, it is particularly important to increase assistance from developed countries. African States are expected to demonstrate the ability to implement policies that will change with the funds received / while receiving funds. However, for various reasons, despite numerous aid packages, it/Africa remains backward. This article examines the impact of foreign aid on agricultural productivity and the impact of the quality of management on development aid flows. As examples, it was decided to take such countries as Ghana, Cameroon and Mali. The purpose of this article is to confirm the hypothesis that development assistance correlates positively with the productivity of agriculture. The second hypothesis suggests that development aid flows respond to the quality of public administration. As for the results, the impact between the variables was recorded, but the results were ambiguous.
\end{abstract}

\section{Keywords}

Africa, official development aid, agriculture, public administration, Ghana, Cameroon, Mali.

Blížkovský, P. and Emelin, R. (2020) "The Impact of Official Development Assistance on the Productivity of Agricultural Production in Ghana, Cameroon and Mali", AGRIS on-line Papers in Economics and Informatics, Vol. 12, No. 2, pp. 29-39. ISSN 1804-1930. DOI 10.7160/aol.2020.120203.

\section{Introduction}

The economies of developing countries are dependent mainly on agriculture. Despite the rapid pace of urbanization, most people in the poorest regions of the world still spend all their lives, or its biggest part, in earning a living in rural areas.

African states are a prime example. Their economic structure still suggests a wide involvement of the agricultural sector to the economy and the bulk of the population still belongs to the category of predominantly rural population. Agriculture is an important sector of the African industry and economy, employs more than half of the population and accounts for more than half of the national income.

According to the long-term forecast of the United Nations (UN) the population of Africa by the midcentury will double. The problem of food security does not lose its importance and standing on the first place in the program of the development of Africa and the world in general. This problem can be solved by increasing the area of arable land, water availability and provision of appropriate infrastructure. Particularly important is the need to increase yields from already existing processed lands, not only increase the number of hectares. It is important to develop a process of sustainable development, but it is difficult without increase of assistance from the developed countries.

Limited investment to African agriculture is one of the main barriers for the expansion of agricultural production in the region. For most of the African countries current domestic investment in agriculture is delayed due to the limitations of the state budget and deficit of accumulated savings. This means that the increase of investment in agriculture is a bottleneck of funds for the development of such important sectors as medicine, education, and so on. Therefore, to fill this gap developing countries need more help from rich or developed countries and other multilateral organizations. 
In today's economic environment the aim of reducing the negative effects of differences in income level between the countries of the rich north and the poor south was acquired by high level of foreign aid or its particular part - official development assistance.

It is expected that African countries will demonstrate the ability to carry out policy that will change them with the help of the funds raised. However, for various reasons, such as the weakness of the government, bad management, corruption and lack of accountability in the implementation of the policies, the region, despite the numerous aid packages, remains backward.

This article examines such countries, as Ghana, Cameroon and Mali, with specific examples of the impact of development aid in Africa; the work also examines in particular the impact of foreign aid on the productivity of agricultural production in these countries, and how it affects the quality of public administration on the flows of development assistance.

The aim of this article is to confirm the hypothesis that development aid positively affects the productivity of agriculture. The second hypothesis assumes that the flows of development assistance respond to the quality of public administration.

\section{Literature overview}

In the literature, due to the diversity of authors and works devoted to research in the field of development, we meet with a variety of terms, such as "foreign aid", "official development assistance" or "development cooperation"; therefore, we consider it appropriate to give a few definitions. One of the most complex definitions of foreign aid or official development assistance (ODA) served the Development Assistance Committee(DAC) of the Organization for economic cooperation and development(OECD), according to which aid includes grants and loans to developing countries and territories, 1) which are determined by the official sector of the country of the donor, 2) aimed at promoting the economic development and welfare in recipient countries as the main objective and 3) provided on favourable financial terms, which must include a subsidy component, which constitute not less than 25 percent. In response to these financial flows in ODA to initiate technical cooperation, even if grants, loans and credits for military purposes are excluded without regard to their concession character (OECD, 2018).
Factors that decrease the effectiveness of foreign aid associate researcher as Abramova (2011) into two groups depending on the performance of donor countries and beneficiaries. She mentions that one of the main reasons of limiting the effectiveness is lack of coordination of the activities of the supplier countries. An example of such a practice is Brazil, where is a system for developing programs in the area of provision of foreign aid and control over their implementation is decentralized. In 1997, the country created the Department for international development with a wide range of powers (Barder, 2005) which resulted in improvements of the aid efficiency.

Another factor reducing the efficiency of the assistance provided is its volatility. Reduction in the volume of foreign aid leads to a reduction of the expenditure of the state budget, mainly through the social sector, and also increasing tax rates, is thus a direct impact on the economic growth of the country (Kapitsa, 2013; Fengler and Kharas, 2011). The complexity of the forecasting of the flows of foreign aid serves as serious limitations on the effectiveness of longterm and medium-term national development strategies in recipient countries. The experience of Mozambique suggests that the ability of forecasting / estimating a three-year period, budget spending was granted in 2007 a limited number of donors active in the country, and the African development bank, Finland, France, Germany and Sweden (Wheeler, 2011).

When examining issues of volatility of development aid, it stresses the positive effect of such practices in the case of armed conflicts or natural disasters in developing countries. In such situations the assistance is mainly focused on solving humanitarian tasks. In 2000, a sharp increase in the volume of provided assistance to Mozambique for flood relief efforts was recorded and in 2002 in Ethiopia due to drought (Markandya et al., 2010).

Another factor is the economic and political situation in the involved recipient country, including the lack of ability of beneficiary countries to properly use the provided funds in the existing level of development, the weakness of the national financial institutions, high level of corruption and the instability of political systems. Corruption was the main theme in most of the literature on foreign aid. An international non-profit non-governmental organization is fighting against corruption. A large part of the corruption in developing countries stems from the flow of funds on the line to help. Help ends 
up in the pockets of corrupt officials in the system of those states where there is lack of responsibility. As has noted development economist Peter Bauer, foreign aid is "an excellent way to transfer money from rich countries to the poor to rich people in poor countries" (Moyo, 2009; Radelet, 2016).

Poor countries suffer not so much from lack of help, as from the low quality of its management. When the United States and other non-governmental organizations such as the UN and the World Bank, are increasing aid to poor countries around the world, it doesn't change the situation, because most of these countries are plagued with corruption (Werlin, 2005). Zambia has received millions of dollars in aid in the period from 1964 to 2000 , but the average income fell from \$ 540 up to $\$ 300$. Zambia receives more aid per capita than any other country, however, an increase in foreign aid in recent years in any case does not affect the standard of living or economics. The author believes that corruption in Africa is the cause of extreme poverty in the region. No matter how much money enters into the economy, if the problem of corruption is not solved, economic growth will not bring any benefits. He claims that the Nigerian state system suffers from corruption and, therefore, the World Bank could just stop borrowing money Nigeria. He also proposes to provide assistance only if the country transforms its civil service, the police and the judiciary (Werlin, 2005).

Easterly (2003) discusses the relationship between the economic policy of the recipient countries and aid effectiveness. He uses the work of Burnside and Dollar (2000) as a guide for his arguments. The author argues that aid stimulates growth in favourable political conditions. Easterly claims that the governments of poor countries do not have incentives to increase the production capacity of the poor population, especially when it can lead to political activity threatening the current political elite.

It is important also to mention such negative effect as the "Dutch disease", which hits the countries receiving assistance. The concept of the Dutch disease represents a negative effect that may strengthen the real exchange rate of the national currency on economic development as a result of the boom in a particular sector. The effect got its name according to the events in Holland in 1950, when deposits of natural gas were discovered, after which the extending export of fuel has resulted in an increase of inflation and unemployment and a reduction in manufacturing exports (Malahova, 2011; Moyo, 2009).
In Africa, lot of foreign aid goes to agriculture. This sector plays a key role in the development of states in sub-Saharan Africa as the main source of income, food, employment and an effective means for poverty reduction. "African bank group" with its strategy "Feed Africa" reported that in 2016 more than $70 \%$ of the population of Africa lives in the rural areas and relied on agriculture as the main source of livelihood. The development of the agricultural sector has a greater impact on poverty reduction compared with growth in non-agricultural sectors (Mellor, 1999; Christiaensen et al, 2011). Africa has the largest share of arable land, yet the continent suffers from high degree of malnutrition. About $20 \%$ of the inhabitants of the continent is not able to meet the daily energy needs and the average African is faced with a lack of food. Food intake represents a 156 kilocalories per person per day (FAO, 2014).

African agricultural systems also show a low level of mechanization. The share of manual labour in agriculture in Africa is $70 \%$. This means that the mechanization of production in agriculture is only $30 \%$. Lack of storage facilities, transport systems and modern slaughterhouses also affects the quality and quantity of African products entering the market. Agricultural businesses in rural agricultural communities reduce postharvest losses and at the same time provide added value to primary agricultural products. This will lead to higher and more stable prices and at the same time it creates more opportunities for employment. This, in turn, will lead primarily to reduction of poverty, the suppression of the growth of the urban population and ensuring a more sustainable development in rural areas (Blizkovsky, 2017). Another area of agricultural development is a functioning infrastructure. Without good roads and other transport facilities, farmers have limited access to markets, which gives them fewer opportunities to sell surpluses and to obtain favourable market prices, as well as buy modern resources. Infrastructure is related with business and export opportunities (Abramova, 2010). Development aid aims at helping increasing the productivity and sustainability of the African agriculture as well as the efficiency of public sector in general. The paper searches for evidence whether it is successful.

\section{Materials and methods}

The established hypothesis has been verified on the basis of correlation analysis using Pearson correlation coefficient $(r)$. It is a measure 
of the linear relationship (magnitude of association) between the variables as well as the direction of the relationship (Emerson, 2015). The correlation analysis has limitations as its result do establish a causal connection between the phenomena.

In addition, we also run a Spearman correlation coefficient. The reason for using this second measure was to deal with the extreme data values. Instead of arbitrary elimination of such values from the Pearson correlation coefficient calculation we used Spearman correlation coefficient. It is a suitable tool for cases of unknown probability distribution (De Winter, Gosling and Potter, 2016).

The value of the correlation coefficient varies in the interval $(-1 ; 1)$ where $r>0$ means a positive relationship between $\mathrm{X}$ and $\mathrm{Y}, r<0$ means a negative relationship and $r=0$ means no relationship (Ratner, 2009). For establishing the level of correlation, we use the following values: $r=0$ linear correlation independence $|r|=0.01-0.30$ weak correlation, $|r|=0.31-0.50$ moderate correlation, $|r|=0.51$ - 0.70 medium correlation, $|r|=0.71-0.90$ high correlation, $|r|=0.91-0.99$ very high correlation and $r=1$ functional correlation (Biskup, 2009).

The statistical significance of both Pearson and Spearman correlation coefficients was evaluated by $\mathrm{p}$-value. In the paper we consider results where $\mathrm{p}<0.05$ (5\% significance level) as statistically significant.

Data were collected from the database of the Credit Reporting System of the OECD (2016) and from FAOSTAT (2016) and World Bank (2016). The time period for this research was provided in the time interval from 2002 until 2016 inclusive. All the indicators used in the study were tested on correlation with the indicator "development assistance to agriculture", that was further divided into three separate indicators: the total official development assistance (ODA) to agriculture, bilateral ODA for agriculture and multilateral ODA to agriculture. The data came from the database of the OECD (2016) and are measured in millions of dollars fixed price.

As a proxy for the productivity of agricultural production were used the cereal yield (kg/ha). This indicator was chosen because it includes large part of the plant production and includes cereals, such as rice, corn, barley, oats, rye, millet, sorghum, buckwheat and mixed grains, most of which is grown in the three studied countries.

For measuring the quality of public administration we used the management indicators of the World
Bank (2018). They range from -2.5 (worst) to 2.5 (best). As indices of the quality of the state administration we selected (1) political stability and absence of violence and (2) control of corruption. The Index Political Stability and Absence of Violence includes indicators that measure the stability of state institutions, the probability of drastic changes, a change in policy, the destabilization and overthrow of the non-constitutional methods or by the use of violence. The index of control of corruption shows the level of use of state power for mercenary purposes, the existence of corruption at a high political level, the level of participation of elites in corruption or impact of corruption on economic development. Both aggregate indicators combine the views of a large number of enterprise, citizen and expert survey respondents in industrial and developing countries. They are based on over 30 individual data sources produced by a variety of survey institutes, think tanks, non-governmental organizations, international organizations, and private sector firms (The World Bank, 2019).

\section{Results and discussion}

The results for correlation between the official development aid to agriculture (bilateral, multilateral and total), agricultural production (expressed by cereal yield), the political stability and absence of violence and the control of corruption are presented for each of the three countries.

\section{The case of Ghana}

In case of Ghana (Figure 1, Table 1) the correlation analysis measured by Pearson coefficient confirmed the hypothesis on the positive impact of the total, multilateral and bilateral foreign aid for the agricultural sector in the country (statistically significant medium correlation).

The correlation between the political stability and absence of violence includes indicators that measure the stability of state institutions, the probability of drastic changes or political destabilization. The results indicate a weak positive and statistically non-significant correlation between the amount of total and multilateral aid Political Stability and Absence of Violence and total and multilateral aid flows for development. In case of the bilateral aid this correlation is even negative (statistically non-significant).

As for corruption, Ghana has achieved considerable success in the fight against corruption with the transition to civilian government in 1992. 
This is confirmed by a positive medium level of correlation between the control of corruption and multilateral and total official development aid (statistically significant). The correlation for bilateral aid was moderate and statistically non-significant).

The Ghana results are the largely confirming the research hypothesis on positive correlation between official aid and selected political indicators as well as on the agricultural productivity.

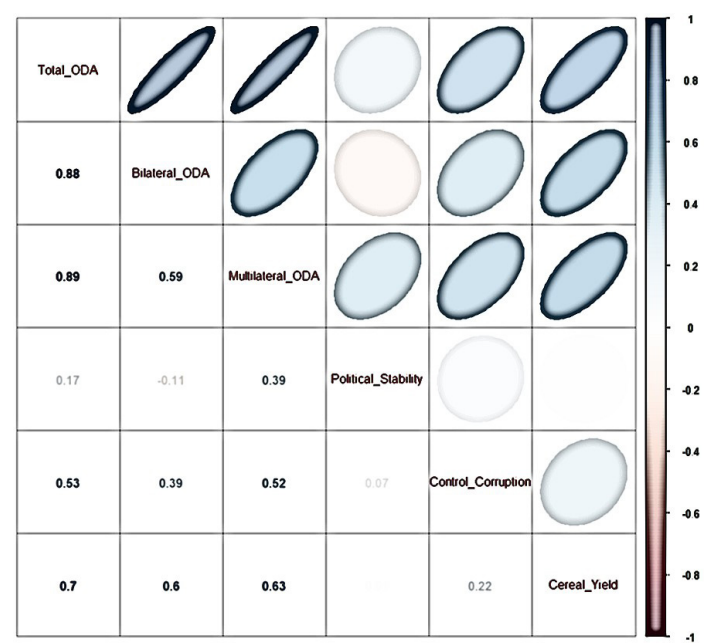

Source: Source: OECD (2016), FAOSTAT (2016) and World Bank (2016)

Figure 1: Correlation between official development aid (bilateral, multilateral and total), the political stability and absence of violence, the control of corruption and agricultural production (expressed by cereal yield) in Ghana for the period 2002-2016 (Pearson coefficient).
The results for Ghana measured by Spearman coefficient (Figure 2, Table 2) provided for a similar correlation pattern as in the case of the Pearson coefficient. The correlation between all types of official aid and political stability and absence of violence was statistically non-significant and weak and even negative (bilateral aid). Also statistically non-significant was the correlation between the official aid and corruption control. Cereal productivity was positive at medium level (statistically significant).

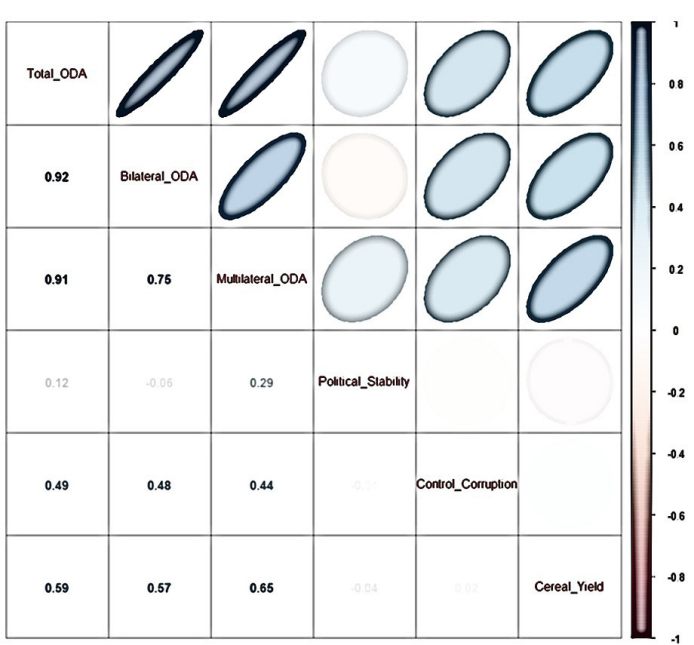

Source: Source: OECD (2016), FAOSTAT (2016) and World Bank (2016)

Figure 2: Correlation between official development aid (bilateral, multilateral and total), the political stability and absence of violence, the control of corruption and agricultural production (expressed by cereal yield) in Ghana for the period 2002-2016 (Spearman coefficient).

\begin{tabular}{|l|c|c|c|c|c|c|}
\hline & Total ODA & Bilateral ODA & Multilateral ODA & Political Stability & Control Corruption & Cereal Yield \\
\hline Total ODA & & $\mathbf{0 . 0 0 0 0}$ & $\mathbf{0 . 0 0 0 0}$ & 0.5534 & $\mathbf{0 . 0 4 1 3}$ & $\mathbf{0 . 0 0 3 4}$ \\
\hline Bilateral ODA & $\mathbf{0 . 0 0 0 0}$ & & $\mathbf{0 . 0 2 0 9}$ & 0.7064 & 0.1529 & $\mathbf{0 . 0 1 7 1}$ \\
\hline Multilateral ODA & $\mathbf{0 . 0 0 0 0}$ & $\mathbf{0 . 0 2 0 9}$ & & 0.1516 & $\mathbf{0 . 0 4 6 9}$ & $\mathbf{0 . 0 1 1 7}$ \\
\hline Political Stability & 0.5534 & 0.7064 & 0.1516 & & 0.816 & 0.9765 \\
\hline Control Corruption & $\mathbf{0 . 0 4 1 3}$ & 0.1529 & $\mathbf{0 . 0 4 6 9}$ & 0.816 & 0.435 \\
\hline Cereal Yield & $\mathbf{0 . 0 0 3 4}$ & $\mathbf{0 . 0 1 7 1}$ & $\mathbf{0 . 0 1 1 7}$ & 0.9765 & 0.435 & \\
\hline
\end{tabular}

Note: p-values bellow 0.05 mean that correlation coefficient je statistically significant on the above $5 \%$ level (in bold). Source: Source: OECD (2016), FAOSTAT (2016) and World Bank (2016)

Table 1: Probability value ( $\mathrm{p}$-value) for the correlations for Ghana for the period 2002-2016 (Pearson coefficient).

\begin{tabular}{|l|c|c|c|c|c|c|}
\hline & Total ODA & Bilateral ODA & Multilateral ODA & Political Stability & Control Corruption & Cereal Yield \\
\hline Total ODA & & $\mathbf{0 . 0 0 0 0}$ & $\mathbf{0 . 0 0 0 0}$ & 0.6757 & 0.0664 & $\mathbf{0 . 0 1 9 8}$ \\
\hline Bilateral ODA & $\mathbf{0 . 0 0 0 0}$ & & $\mathbf{0 . 0 0 1 3}$ & 0.8298 & 0.0687 & $\mathbf{0 . 0 2 7 2}$ \\
\hline Multilateral ODA & $\mathbf{0 . 0 0 0 0}$ & $\mathbf{0 . 0 0 1 3}$ & & 0.2957 & 0.1014 & $\mathbf{0 . 0 0 8 7}$ \\
\hline Political Stability & 0.6757 & 0.8298 & 0.2957 & & 0.9698 & 0.8894 \\
\hline Control Corruption & 0.0664 & 0.0687 & 0.1014 & 0.9698 & 0.9496 \\
\hline Cereal Yield & $\mathbf{0 . 0 1 9 8}$ & $\mathbf{0 . 0 2 7 2}$ & $\mathbf{0 . 0 0 8 7}$ & 0.8894 & 0.9496 & \\
\hline
\end{tabular}

Note: p-values bellow 0.05 mean that correlation coefficient je statistically significant on the above $5 \%$ level (in bold).

Source: Source: OECD (2016), FAOSTAT (2016) and World Bank (2016)

Table 2: Probability value (p-value) for the correlations for Ghana for the period 2002-2016 (Spearman coefficient) 


\section{Case of Cameroon}

As for Cameroon, measured by Pearson coefficient (Figure 3, Table 3), there is a multilateral development assistance at weak positive and statistically non-significant level $(r=0.07)$, but bilateral and total foreign aid has a negative effect $(r=-0.27$ and $r=-0,16)$.

The correlation between official development aid and political stability and absence of violence was even negative at moderate (bilateral aid) and medium levels for total aid $(r=-0.63$, statistically significant) and multilateral aid $(r=-0.73$, statistically significant).

Also the correlation between official development aid and control of corruption was negative although at a weak and statistically non-significant levels.

Unlike the case of Ghana, the results are not confirming the research hypothesis on positive correlation between official aid and selected political indicators as well as on the agricultural productivity.



Source: Source: OECD (2016), FAOSTAT (2016) and World Bank (2016)

Figure 3. Correlation between official development aid

(bilateral, multilateral and total), the political stability and absence of violence, the control of corruption and agricultural production (expressed by cereal yield) in Cameroon for the period 2002-2016 (Pearson coefficient).
The results for Cameroon measured by Spearman coefficient (Figure 4, Table 4) given comparable correlation results as it was the case of the Pearson coefficient. The correlation between all typed of official aid and political stability and absence of violence was negative. It correlation was at moderate level and statistically significant on case of total aid $(r=-0.57)$ and multilateral aid $(r=-0,71)$. The correlation between the official aid and corruption control was statistically non-significant, negative and weak. Cereal productivity correlated negatively with total $(r=-0.22)$ and bilateral aid $(r=-0.56$, statistically significant).

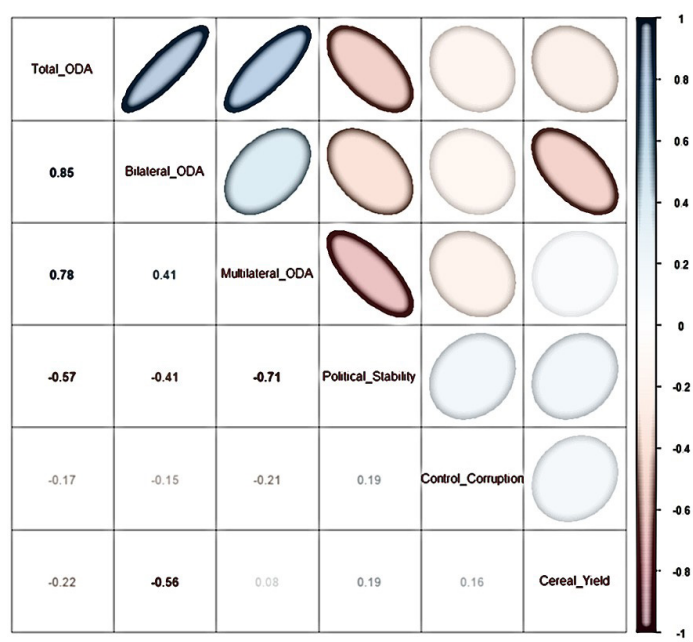

Source: Source: OECD (2016), FAOSTAT (2016) and World Bank (2016)

Figure 4: Correlation between official development aid (bilateral, multilateral and total), the political stability and absence of violence, the control of corruption and agricultural production (expressed by cereal yield) in Cameroon for the period 2002-2016 (Spearman coefficient).

\begin{tabular}{|l|c|c|c|c|c|c|}
\hline & Total ODA & Bilateral ODA & Multilateral ODA & Political Stability & Control Corruption & Cereal Yield \\
\hline Total ODA & & $\mathbf{0 . 0 0 0 0}$ & $\mathbf{0 . 0 0 0 5}$ & $\mathbf{0 . 0 1 2 1}$ & 0.4322 & 0.5709 \\
\hline Bilateral ODA & $\mathbf{0 . 0 0 0 0}$ & & 0.0823 & 0.1228 & $0.69 \mathrm{ncs} 147$ & 0.0171 \\
\hline Multilateral ODA & $\mathbf{0 . 0 0 0 5}$ & 0.0823 & & $\mathbf{0 . 0 0 2 2}$ & 0.2679 & 0.8147 \\
\hline Political Stability & $\mathbf{0 . 0 1 2 1}$ & 0.1228 & $\mathbf{0 . 0 0 2 2}$ & & 0.4593 & 0.4165 \\
\hline Control Corruption & 0.4322 & 0.6947 & 0.2679 & 0.4593 & 0.4718 \\
\hline Cereal Yield & 0.5709 & 0.3256 & 0.8147 & 0.4165 & 0.4718 & \\
\hline
\end{tabular}

Note: p-values bellow 0.05 mean that correlation coefficient je statistically significant on the above $5 \%$ level (in bold). Source: Source: OECD (2016), FAOSTAT (2016) and World Bank (2016)

Table 3: Probability value (p-value) for the correlations for Cameroon for the period 2002-2016 (Pearson coefficient). 


\begin{tabular}{|l|c|c|c|c|c|c|}
\hline & Total ODA & Bilateral ODA & Multilateral ODA & Political Stability & Control Corruption & Cereal Yield \\
\hline Total ODA & & $\mathbf{0 . 0 0 0 0}$ & $\mathbf{0 . 0 0 0 6}$ & $\mathbf{0 . 0 2 4 9}$ & 0.5327 & 0.4277 \\
\hline Bilateral ODA & $\mathbf{0 . 0 0 0 0}$ & & 0.1320 & 0.1320 & 0.5848 & $\mathbf{0 . 0 2 8 4}$ \\
\hline Multilateral ODA & $\mathbf{0 . 0 0 0 6}$ & 0.1320 & & $\mathbf{0 . 0 0 3 0}$ & 0.4588 & 0.7710 \\
\hline Political Stability & $\mathbf{0 . 0 2 4 9}$ & 0.1320 & $\mathbf{0 . 0 0 3 0}$ & & 0.4910 & 0.4910 \\
\hline Control Corruption & 0.5327 & 0.5848 & 0.4588 & 0.4910 & & 0.5760 \\
\hline Cereal Yield & 0.4277 & $\mathbf{0 . 0 2 8 4}$ & 0.7710 & 0.4910 & 0.5760 & \\
\hline
\end{tabular}

Note: p-values bellow 0.05 mean that correlation coefficient je statistically significant on the above $5 \%$ level (in bold).

Source: Source: OECD (2016), FAOSTAT (2016) and World Bank (2016)

Table 4: Probability value (p-value) for the correlations for Cameroon for the period 2002-2016 (Spearman coefficient).

\section{Case of Mali}

For Mali the correlation analysis measured by Pearson coefficient (Fig. 5, Tab. 5) showed that the agricultural productivity measured by cereal yields was positive for all types of development assistance. The strongest correlation was for the total aid ( $r=0.60$, statistically significant). Positive addiction agriculture in Mali on bilateral aid can be explained using a number of aid donor countries. Between 2002 and 2016 provided by donor countries to 1.01 billion dollars for the development of agriculture, compared with 693 million dollars provided by the international organizations (OECD, 2016).

The correlation between the political stability and absence of violence includes indicators that measure the stability of state institutions, the probability of drastic changes or political destabilization. The results indicate a weak positive and statistically non-significant correlation between the amount of total and multilateral aid Political Stability and Absence of Violence and total and multilateral aid flows for development. In case of the bilateral aid this correlation is even negative (statistically non-significant).

As for corruption, Ghana has achieved considerable success in the fight against corruption with the transition to civilian government in 1992 . This is confirmed by the a positive medium level of correlation between the control of corruption and multilateral and total official development aid (statistically significant). The correlation for bilateral aid was moderate and statistically non-significant).

Similarly to Cameroon, also in Mali the correlation between political stability and absence of violence coefficient and official aid was moderately negative (statistically non-significant). shows a value of $r=-0.43$ and $r=-0.53$. This negative correlation dependence can be explained by a possibility that the raising funds for the development plays an influence of panacea. The negative dependence in Mali can also be explained by the fact that the instability caused by the conflict was observed on the northeast of the country, where there had been virtually no active agricultural activities.

Also the control of corruption and official aid correlation was weakly negative (statistically non-significant). This can indicate that the donors aid is insufficiently linked with the anti-corruption mechanisms.

The results are not confirming the research hypothesis on positive correlation between official aid and selected political indicators. The research hypothesis can be however confirmed for the case of the agricultural productivity.

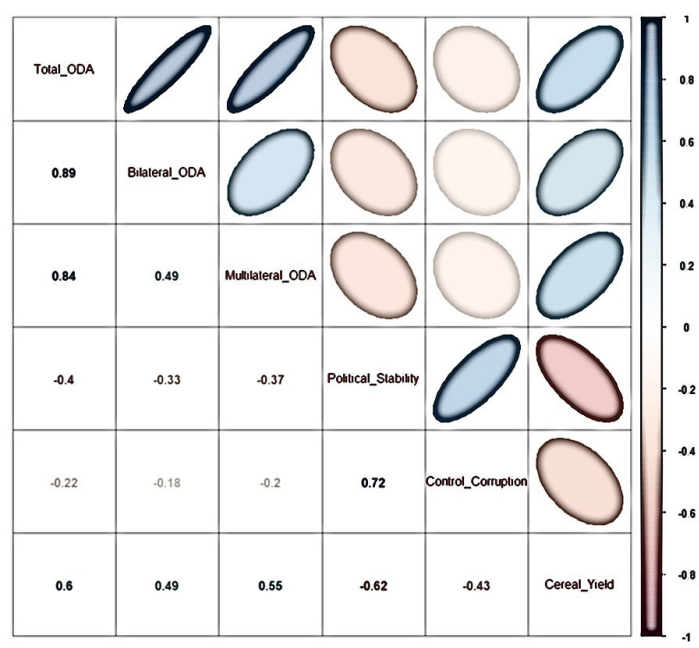

Source: Source: OECD (2016), FAOSTAT (2016) and World Bank (2016)

Figure 5: Correlation between official development aid (bilateral, multilateral and total), the political stability and absence of violence, the control of corruption and agricultural production (expressed by cereal yield) in Mali for the period 2002-2016 (Pearson coefficient).

The results for Mali measured by Spearman coefficient (Figure 6, Table 6) are very close of those obtained by analysis based on Pearson coefficient. 


\begin{tabular}{|l|c|c|c|c|c|c|}
\hline & Total ODA & Bilateral ODA & Multilateral ODA & Political Stability & Control Corruption & Cereal Yield \\
\hline Total ODA & & $\mathbf{0 . 0 0 0 0}$ & $\mathbf{0 . 0 0 0 0}$ & 0.1348 & 0.4213 & $\mathbf{0 . 0 1 8 7}$ \\
\hline Bilateral ODA & $\mathbf{0 . 0 0 0 0}$ & & 0.0635 & 0.2325 & 0.5285 & 0.0662 \\
\hline Multilateral ODA & $\mathbf{0 . 0 0 0 0}$ & 0.0635 & & 0.1765 & 0.4649 & $\mathbf{0 . 0 3 1 9}$ \\
\hline Political Stability & 0.1348 & 0.2325 & 0.1765 & & $\mathbf{0 . 0 0 2 7}$ & $\mathbf{0 . 0 1 2 8}$ \\
\hline Control Corruption & 0.4213 & 0.5285 & 0.4649 & $\mathbf{0 . 0 0 2 7}$ & & 0.1064 \\
\hline Cereal Yield & $\mathbf{0 . 0 1 8 7}$ & 0.0662 & $\mathbf{0 . 0 3 1 9}$ & $\mathbf{0 . 0 3 1 9}$ & 0.1064 & \\
\hline
\end{tabular}

Note: p-values bellow 0.05 mean that correlation coefficient je statistically significant on the above $5 \%$ level (in bold). Source: Source: OECD (2016), FAOSTAT (2016) and World Bank (2016)

Table 5: Probability value (p-value) for the correlations for Mali for the period 2002-2016 (Pearson coefficient).

\begin{tabular}{|l|c|c|c|c|c|c|}
\hline & Total ODA & Bilateral ODA & Multilateral ODA & Political Stability & Control Corruption & Cereal Yield \\
\hline Total ODA & & $\mathbf{0 . 0 0 0 1}$ & $\mathbf{0 . 0 0 0 0}$ & $\mathbf{0 . 0 3 2 3}$ & 0.5243 & $\mathbf{0 . 0 4 1 2}$ \\
\hline Bilateral ODA & $\mathbf{0 . 0 0 0 1}$ & & $\mathbf{0 . 0 3 1 0}$ & 0.0598 & 0.4201 & 0.0664 \\
\hline Multilateral ODA & $\mathbf{0 . 0 0 0 0}$ & $\mathbf{0 . 0 3 1 0}$ & & 0.0577 & 0.6296 & $\mathbf{0 . 0 3 2 3}$ \\
\hline Political Stability & $\mathbf{0 . 0 3 2 3}$ & 0.0598 & 0.0577 & & $\mathbf{0 . 0 0 3 4}$ & $\mathbf{0 . 0 1 4 8}$ \\
\hline Control Corruption & 0.5243 & 0.4201 & 0.6296 & $\mathbf{0 . 0 0 3 4}$ & & 0.1110 \\
\hline Cereal Yield & $\mathbf{0 . 0 4 1 2}$ & 0.0664 & $\mathbf{0 . 0 3 2 3}$ & $\mathbf{0 . 0 1 4 8}$ & 0.1110 & \\
\hline
\end{tabular}

Note: p-values bellow 0.05 mean that correlation coefficient je statistically significant on the above $5 \%$ level (in bold). Source: Source: OECD (2016), FAOSTAT (2016) and World Bank (2016)

Table 6: Probability value (p-value) for the correlations for Mali for the period 2002-2016 (Spearman coefficient).

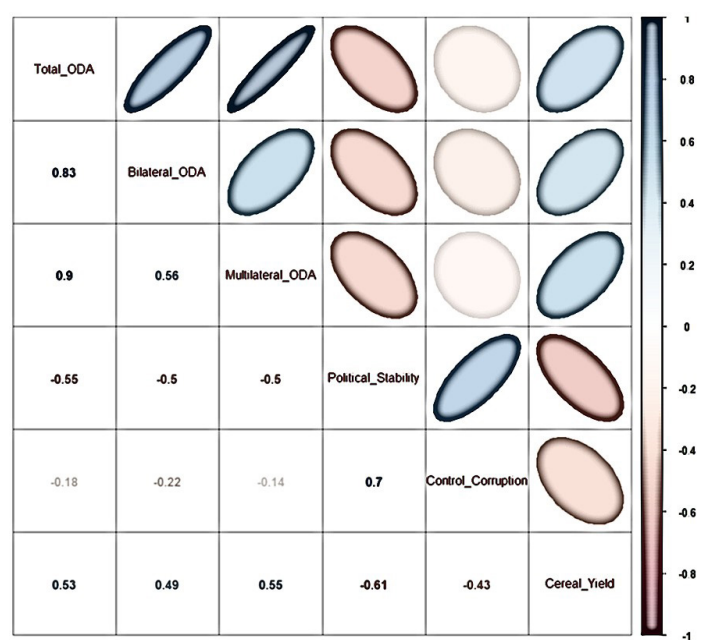

Source: Source: OECD (2016), FAOSTAT (2016) and World Bank (2016)

Figure 6: Correlation between official development aid

(bilateral, multilateral and total), the political stability and absence of violence, the control of corruption and agricultural production (expressed by cereal yield) in Mali for the period 2002-2016 (Spearman coefficient).

Our analysis can be translated as having the following economic, social and political impact. Economically speaking, the performance of agriculture can be improved via more effective foreign aid. Societally, the sustainability risk related to the agricultural production is increasing. Therefore, the volume of financial resources should increase to the development of agricultural research, which is focused on the development of resistant seeds and modern methods and technologies of work with the soil, which will increase the yields of food agricultural crops, such as rice, yam, cassava, millet and more. Also, due to the gradual climate change should increase the volume of financial resources on the development of irrigation infrastructure and water resources. It will be important to increase funding for post-harvest losses.

The political aspect of the problem of development assistance to foreign aid could solve the current agricultural problems in Ghana, Cameroon and Mali, and it requires strong political will. Deficiencies in this respect is one of the main reasons for the incorrect allocation of foreign aid. Foreign aid will work best in countries with good policies and institutions, such as Ghana. Similarly, the improved agricultural performance is likely to contribute to the stabilization of the political situation in the given country.

\section{Discussion}

This paper examined the effects of agricultural development assistance on agricultural productivity in Ghana, Cameroon and Mali. The paper had a regional focus in comparison with the researches of a number of authors who have dealt with the influence of foreign aid on a global level (Alabi, 2014; Ssozi et al., 2017). For example, Alabi examined the impact of foreign aid on agricultural productivity on the example of the 47 countries in Africa. The results of the regional and global studies have varied results. As for the impact of bilateral 
aid on agricultural productivity, he has in the three countries and at the global level assistance from the DAC a significant impact on agricultural productivity.

As far as the multilateral agricultural aid on agricultural productivity, at the global level revealed no significant addiction. But in this study help from organisations has a significant impact in Ghana and less of an impact on Mali. Alabi (2014) explains this by saying that the volume of bilateral aid is usually higher than the volumes of multilateral assistance. A regional example of Ghana, however, shows the opposite trend. It gives impetus to the study of the impact of both forms of assistance on the example of other countries in the African continent.

The example of Cameroon and Mali has confirmed a match with some of the authors that despite the constant high level of corruption, financial support will be provided and it may be increased (Alabi, 2014; De la Croix and Delavallade, 2013). The quality of public administration in the case of Ghana, however, endorsed the proposal of several authors, that the assistance will be effective and will increase in the country, where there are good governance (Knack, 2001; Collier and Dollar, 2001).

Based on the analysis of countries such as Ghana, Cameroon and Mali, and its results, we would like to offer a series of recommendations.

The primary recommendation would be the growth in the volume of foreign agricultural aid with a view to increase its impact on the performance of agriculture and its contribution to the economy of Ghana and Mali. It will be important to increase the volume of agricultural development assistance from both donor countries and the international organizations. In case of Cameroon, the weak correlation between foreign aid to agriculture sector and actual agricultural productivity means that there are other limiting factors hampering the agricultural growth than the inflow of capital to the sector. We suppose that these systemic blocks should be removed by Cameroon before external aid increase.

It will be essential to grow the volume of agricultural aid to those subsectors of agriculture of Ghana and Mali, which carry the most risk for agricultural productivity. The volume of financial resources should advance the development of agricultural research, which is focused on the development of resistant seeds and modern methods and technologies of work with the soil, which will increase the yields of food agricultural crops, such as rice, yam, cassava, millet and more. Also, due to the gradual climate change, the volume of financial resources on the development of irrigation infrastructure and water resources should be improved. It will be important to increase funding for post-harvest losses.

What concerns the political aspect of the problem of development assistance to foreign aid could solve the current agricultural problems in Ghana, Cameroon and Mali, it is the necessary strong political will for the implementation of good public policy practice. A large part of the literature confirms that the objectives in the field of economy and development goes hand in hand with the political objectives. This is one of the main reasons for the incorrect allocation of foreign aid. Foreign aid will work best in countries with good policies and institutions, as in Ghana.

\section{Conclusion}

The paper focused on the analysis of the impact of development aid on the productivity of agricultural production in Ghana, Cameroon and Mali. The role of agriculture in the economic development of the African continent was analysed and it was shown that agriculture plays a leading role in the economic development of the continent. In addition, the main problems of its development were analysed, with an emphasis on sub-Saharan Africa. The aim of work was to determine: 1) whether the development assistance positively correlates with the productivity of agriculture and 2) whether the quality of public administration correlates with the flows of development assistance. For the analysis of the total assistance in the area of agricultural development divided into bilateral and multilateral, to determine which of them has the greatest impact. The analysis showed that the development aid correlated positively with agricultural productivity measured by cereal yields in Ghana and Mali. The multilateral agricultural aid correlated most with the agricultural productivity. In Cameroon, no significant correlation was observed.

When it comes to "political" hypothesis, here we analysed the effects of the quality of public administration on the flows of agricultural aid. In Ghana, the hypothesis was confirmed that the volume of assistance provided depends on the quality of public administration. As for Cameroon and Mali the aid flows have a negative and/or non-significant dependence on the quality of public administration. 
Corresponding authors

Petr Bližkovský

General Secretariat of the Council of the European Union, Rue de la Loi/Wetstraat 175, Brussels, Belgium

E-mail:petr.blizkovsky@cor.europa.eu

\section{References}

[1] Abramova, I. (2010) "African economy in the context of market transformation", Moscow, African Institute of the Russian Academy Of Sciences

[2] Abramova, A. (2011) "Foreign Aid Effectiveness: Constraining Factors and Approaches to Its Evaluation", Vestnik MGIMO-Universiteta, Vol. 19, No. 4, pp. 105-113 [Online]. Available: http://www.vestnik.mgimo.ru/sites/default/files/vestnik/2011-19-4.pdf [Accessed: Sept. 15, 2019].

[3] Alabi, R. (2014) "Impact of Agricultural Foreign Aid on Agricultural Growth in Sub-Saharan Africa: A Dynamic Specification", AGRODEP Working Paper 0006, 1-39 [Online]. Available: http:/www.ifpri.org/publication/impact-agricultural-foreign-aid-agricultural-growth-sub-saharanafrica-dynamic. [Accessed: Sept. 20, 2019].

[4] Barder, O. (2005) "Reforming Development Assistance: Lessons from the U.K. Experience", Center for Global Development Working Paper No. 70., 39 p. [Online]. Available: https://www.cgdev. org/publication/reforming-development-assistance-lessons-uk-experience-working-paper-70. [Accessed: Aug. 16, 2019]. DOI 10.2139/ssrn.984062.

[5] Biskup, R. (2009) "Statistika - Regresní a korelační analýza - Úvod do problému", South-Bohemian University ČEské Budějovice, Economic Faculty. [Online]. Available: http://www2.ef.jcu. cz/ birom/stat/prednasky/17.pdf [Accessed: April 8, 2019].

[6] Blizkovsky, P. (2017) "Where are African agricultural policies heading and how does this influences migration?", Acta Universitatis Agriculturae et Silviculturae Mendelianae Brunensis, Vol. 65, No. 5, pp. 1631-1641. E-ISSN 2464-8310, ISSN 1211-8516. DOI 10.11118/actaun201765051631.

[7] Burnside, C. and Dollar, D. (2000) "Aid, policies, and growth", American Economic Review, Vol. 90, No. 4, pp. 847-868. E-ISSN 1944-7981, ISSN 0002-8282. DOI 10.1257/aer.90.4.847.

[8] Christiaensen, L., Demery, L. and Kuhl, J. (2011) "The (evolving) role of agriculture in poverty reduction-An empirical perspective", Journal of Development Economics, Vol. 96, No. 2, pp. 239-254. ISSN 0304-3878. DOI 10.1016/j.jdeveco.2010.10.006.

[9] De Winter, J. C. F., Gosling, S. D. and Potter, J. (2016) "Comparing the Pearson and Spearman correlation coefficients across distributions and sample sizes: A tutorial using simulations and empirical data", Psychological Methods, Vol 21, No. 3, pp. 273-290. E-ISSN 1939-1463, ISSN 1082-989X. DOI 10.1037/met0000079.

[10] Easterly, W. (2003) "Can foreign aid buy growth?", Journal of Economic Perspectives, Vol. 17, No. 3, pp. 23-48. ISSN08953309. DOI 10.1257/089533003769204344.

[11] Emerson, R. W. (2015) "Causation and Pearson's Correlation Coefficient", Journal of Visual Impairment \& Blindness, Vol. 109, No. 3, pp. 242-244. E-ISSN 1559-1476, ISSN: 0145-482X. DOI 10.1177/0145482X1510900311.

[12] FAO (2014) "Report of the high-level panel of experts on food security and nutrition (HLPE): Food losses and waste in the context of sustainable food systems". [Online]. Available: http://www.fao. org/3/a-i3901r.pdf [Accessed: Sept. 20, 2019].

[13] Fengler, W. and Kharas, H. (2011) "Delivering Aid Differently - Lessons from the Field", Economical Premise, No. 49, pp. 1-8. [Online]. Available: https://openknowledge.worldbank.org/bitstream/ha ndle/10986/10108/595510BRI01PUBLIC10BOX358284B0EP49.pdf? sequence=1\&isAllowed=y [Accessed: Sept. 20, 2019]. E-ISBN 978-0-8157-0481-2. 
[14] Kapitsa, L. (2013) "Foreign aid" [Online]. Available: https://www.academia.edu/8218711/ Иностранная_помощь_Foreign_AID_Textbook [Accessed: May 16, 2019].

[15] Malahova, O. (2011) "The Dutch disease in Russia: myth or threat?", Topical Issues of Economics and Management: Materials International. Scientific. Conf. Moscow: Rior

[16] Markandya, A., Yi, S. and Ponczek, V. (2010) "What Are the Links between Aid Volatility and Growth?", Policy Research Working Paper No. 5201, World Bank, Washington. [Online]. Available: https://openknowledge.worldbank.org/handle/10986/19914. [Accessed: May 20, 2019].

[17] Morgenthau, H. (1962) "A Political Theory of Foreign Aid", American Political Science Review, Vol. 56, No. 2, pp. 301-309. E-ISSN 1537-5943, ISSN 0003-0554. DOI 10.2307/1952366.

[18] Moyo, D. (2009) "Dead Aid", London, Penguin Books. ISBN 10: 0374139563, ISBN 13: 9780374139568.

[19] Njeru, J. (2003) "The impact of foreign aid on public expenditure: The case of Kenya. Nairobi", African Economic Research Consortium. ISBN 9966-944-23-0.

[20] OECD (2018) "Official development assistance - definition and coverage". [Online]. Available: http://www.oecd.org/dac/stats/officialdevelopmentassistancedefinitionandcoverage.htm [Accessed: May 15, 2019].

[21] Radelet, S. (2016) "Prosperity rising the success of global development-and how to keep it going", Foreign Affairs, Vol. 95, No. 1, pp. 85-95. ISSN 0015-7120.

[22] Rahn, R. (2003) "Turn Off Foreign Aid?", The Washington Times, [Online]. Available: https://www.chegg.com/homework-help/questions-and-answers/turn-foreign-aid-r-ichard-w-rahnarticle-published-washington-times-sept-2-2003-give-forei-q9630479 [Accessed: April 10, 2019].

[23] Ratner, B. (2009) "The correlation coefficient: Its values range between + 1/ - 1, or do they?", Journal of Targeting, Measurement and Analysis for Marketing, Vol. 17, No. 2, pp. 139-142. E-ISSN 1479-1862. DOI 10.1057/jt.2009.5.

[24] Ssozi, J., Amavilah, H. and Simplice, A. (2017) "Is Aid for Agriculture Effective in Sub-Saharan Africa?", MPRA paper 83073, [Online]. Available: https://mpra.ub.uni-muenchen.de/83073/ [Accessed: May 16, 2019].

[25] The World Bank (2018) "World Bank Open Data". [Online]. Available: https://data.worldbank.org/ [Accessed: May 16, 2019].

[26] The World Bank (2019) "World Bank Open Data", [Online]. Available: https://info.worldbank.org/ governance/wgi/\#home [Accessed: May 16, 2019].

[27] Werlin, H. (2005) "Corruption and foreign aid in Africa", Orbis, No. 49, No. 3, pp. 517-527. ISSN: 0030-4387, DOI 10.1016/j.orbis.2005.04.009.

[28] Wheeler, M. (2011) "Human Resources for Health Observer: Efficiency and effectiveness of aid flows towards health workforce development", Geneva, WHO Press. ISBN 9789241500944. 